\title{
Perfil psicológico de prestação dos futebolistas moçambicanos
}

\section{Psychological performance profile of Mozambican football players}

\author{
P. Saveca, V. Tembe, J. Vasconcelos-Raposo
}

ARTIGO ORIGINAL | ORIGINAL TITLE

\begin{abstract}
RESUMO
O presente estudo teve como objetivo comparar por grupo etário, sexo, nível competitivo, posição de jogo e anos de prática de futebol dos futebolistas moçambicanos em função do perfil psicológico de prestação avaliado pela autoconfiança, pensamentos negativos, atenção, imagética, motivação, pensamentos positivos e atitude competitiva. A amostra foi constituída por 443 praticantes de futebol pertencentes a 32 clubes, sendo 196 (44.2\%) femininos e 247 (55.8\%) masculinos, com idades compreendidas entre os 16 e os 37 anos. Para a realização do estudo foi aplicada a versão traduzida e validada para a língua portuguesa do Psychological Performance Inventory. Os resultados evidenciaram a autoconfiança como o skill mais desenvolvido nestes futebolistas, enquanto a preparação mental média revelou-se assistemática. Face aos resultados conclui-se que os futebolistas moçambicanos participantes neste estudo têm uma preparação mental bastante ténue $(\leq 19)$, sugerindo a necessidade de integrar o treino mental nas suas rotinas diárias de treino para melhorar o skill psicológico.
\end{abstract}

Palavras-chave: perfil psicológico, futebolistas, prestação desportiva

\begin{abstract}
The present study aimed to compare by age group, gender, competitive level, playing position and years of football practice of Mozambican footballers according to the psychological performance profile assessed by self-confidence, negative thoughts, attention, imagery, motivation, positive thoughts and competitive attitude. The sample consisted of 443 soccer players from 32 clubs, 196 (44.2\%) of whom were female and 247 (55.8\%) male, aged between 16 and 37 years. To carry out the study, the translated and validated version for the Portuguese language of the Psychological Performance Inventory was applied. The results showed self-confidence as the most developed skill in these footballers, while the average mental preparation proved to be unsystematic. In view of the results, it is concluded that the Mozambican soccer players participating in this study have a very tenuous mental preparation $(\leq 19)$, suggesting the need to integrate mental training in their daily training routines to improve psychological skill.
\end{abstract}

Keywords: psychological profile, footballers, sports performance

Submitted: 07.28.2020 | Accepted: 09.24.2020

Paulo Tibério Armando Saveca. Escola Superior de Ciências do Desporto, Universidade Eduardo Mondlane, Mozambique. e-mail: paulo.saveca@uem.mz

Vicente Alfredo Tembe. Faculdade de Educação Física e Desporto, Universidade Pedagógica de Maputo, Mozambique. e-mail: vicenteatembe@gmail.com

José Jacinto Vasconcelos-Raposo. Escola de Ciências Humanas e Sociais, Universidade de Trás-os-Montes e Alto Douro. Vila Real, Portugal.

e-mail: j.vasconcelos.raposo@gmail.com 
Nos últimos anos, os atletas têm merecido uma atenção muito especial por parte da ciência, da tecnologia, da economia e da imprensa. A nível mundial o futebol envolve direta ou indiretamente milhões de pessoas, entre praticantes e adeptos, para além dos múltiplos e incalculáveis recursos humanos e materiais nas mais variadas áreas (Murad, 2007). Especificamente, em Moçambique, o futebol é a modalidade desportiva com maior número de adeptos, de praticantes e de recintos desportivos. Por outro lado, os treinadores de futebol em Moçambique têm sido desafiados pela opinião pública, que argumentam que o insucesso no rendimento das suas equipas poderá estar relacionado com fatores psicológicos, assim como a outros fatores e requisitos que influenciam, de uma forma ou outra, o rendimento desportivo. Os argumentos populares são avançados na maioria das vezes, sem que os seus autores tenham os conhecimentos básicos de Psicologia do Desporto. Infelizmente, apenas durante grandes acontecimentos desportivos é que o público ouve falar da psicologia e da sua importância no rendimento desportivo (Vasconcelos-Raposo, 1993).

Atualmente, verificamos um acréscimo na integração de psicólogos nas equipas técnicas das seleções desportivas moçambicanas, com especial ênfase ao futebol. No entanto, continuamos a desconhecer qualquer tipo de estudo ou avaliação que se tenha realizado relativamente ao perfil psicológico dos atletas. Contudo, a integração de psicólogos não se verifica da mesma maneira ao nível dos clubes moçambicanos. Este facto torna mais complexa a possibilidade de uma preparação psicológica dos atletas pois, é no clube onde se desenvolve o nível competitivo, assim como onde se prepara os atletas para lidarem com as adversidades com os atletas se deparam para poderem atingir níveis elevados de rendimento. Deverá nos clubes que os níveis de performance devem estar sujeitos à preparação para poderem responder adequadamente às diversas fontes de pressão psicológica (Rebelo, 1999). Um número significativo dos clubes moçambicanos delega ao treinador principal o papel do psicólogo sem este, no entanto, ter os conhecimentos da Psicologia do Desporto, nem tão pouco conhecimentos técnicos e científicos para avaliar o perfil psicológico dos seus atletas.

O perfil psicológico de um indivíduo é uma designação usada para analisar as várias competências e qualidades psicológicas existentes para uma determinada ação ou atividade. De acordo com Moreira e Vasconcelos-Raposo (2012), o Perfil Psicológico de Prestação (PPP) permite identificar os níveis de preparação nas diferentes componentes psicológicas (autoconfiança, controlo do negativismo, atenção, imagética, motivação, pensamentos positivos e atitude competitiva). Segundo os mesmos autores, a obtenção de valores elevados, nestas componentes psicológicas, tende a estar associada a prestações desportivas mais consistentes, de onde, conhecendo o nível de preparação dos atletas, é possível planear e elaborar intervenções mais adequadas às necessidades e especificidades de cada desportista.

Conhecer o PPP de um atleta torna-se, pois, fundamental para um melhor acompanhamento e orientação do seu desempenho durante a prática desportiva, com vista a alcançar melhores rendimentos. Na verdade, como afirma Bodas, Lázaro e Fernandes (2007), a compreensão e a determinação das componentes psicológicas geradoras de diferenças de rendimento nos momentos de competição revela-se fundamental para o desenvolvimento de intervenções adequadas ao nível do treino desportivo. De acordo com Vasconcelos-Raposo (2003), cada atleta tem um estado psicológico aceitável para a sua prestação, sendo o mesmo determinado por múltiplas variáveis que contribuem para a caracterização do atleta quanto ao nível da sua prestação.

Para Williams (1991), é pertinente conhecer 
se existe um estado psicológico ótimo para realizar execuções plenas. Apesar de existirem diferenças entre indivíduos, na maior parte dos casos, este perfil geral está definido por seis características, nomeadamente (i) alta confiança em si mesmo; (ii) preocupação positiva pelo desporto (imaginação e pensamento); (iii) determinação e compromisso; (iv) autorregulação do nível de ativação (enérgico, mas relaxado, não temeroso); (v) concentração (focalizada apropriadamente) e (vi) autocontrole natural.

De forma similar, Vasconcelos-Raposo (1991) e Hogg (2001) também referenciaram um estado ótimo ou ideal de prestação desportiva. Para o primeiro autor, a manifestação desse estado é caracterizada por músculos "soltos", movimentos fáceis e precisos, sentimentos de autoconfiança, otimismo e atitude positiva. Todas estas variáveis deverão estar harmoniosamente integradas entre o corpo e a mente, para que, na altura da competição, o atleta não questione o que vai fazer ao longo da prova. Por seu lado, Hogg (2001) sustenta que o estado ideal de prestação desportiva é alcançado quando os atletas se sentem completamente preparados e prontos para realizarem as tarefas da sua modalidade de uma forma controlada e consistente. Ainda na opinião de Krane e Williams (2006) os fatores psicológicos determinantes para alcançar a excelência desportiva são a elevada confiança, concentração na tarefa, olhar para as adversidades como um desafio, o perfeccionismo, as atitudes positivas, as cognições sobre desempenho e a forte determinação e compromisso. Além disso, MacNamara, Button e Collins (2010), acrescentam ainda, que a chave do sucesso reside na capacidade dos atletas para lidar com a pressão e na habilidade de se manterem no topo, para além da habilidade de saber sobre a importância do trabalho para se "chegar lá”. Segundo Loehr (1986), os desportistas do mesmo nível competitivo deverão apresentar um perfil psicológico idên- tico, devendo os valores mais elevados serem obtidos pelos atletas de nível de prestação desportiva superior. Este autor ainda defende que há pelo menos oito condições mentais essenciais para que um atleta constitua um estado ideal que aumente as suas possibilidades de obtenção de uma prestação de excelência, quais sejam: estarem mentalmente calmos, fisicamente descontraídos, autoconfiantes e otimistas, elevada concentração no presente, índice elevado de energia, alerta mental e autocontrolo.

Garfield e Bennett (1984), após terem realizado entrevistas a atletas profissionais, também identificaram oito condições mentais e físicas que os atletas descreveram como qualidades das sensações que experimentavam naqueles instantes em que realizavam algo que era extraordinariamente bom: relaxado mentalmente, fisicamente, confiante/ otimistas, centrado no presente, carregado de energia, consciência extraordinária, sob controlo e concentração. Estas características comuns, tomadas como qualidades psicológicas geraram numerosas investigações e práticas (Williams, 1991). Para o mesmo autor, antes de concluir que a presença de um clima emocional adequado ajuda a mobilizar as reações psicológicas que são essenciais para uma execução brilhante, um clima psicológico negativo, como por exemplo, sentimento de frustração, medo e preocupação, conduzem a prestações menos conseguidas. Portanto, torna-se evidente que uma boa prestação tende a estar intimamente associada a uma boa preparação e estado psicológico do indivíduo.

De acordo com Vasconcelos-Raposo (1993), o treino mental visa maximizar o uso pleno das capacidades humanas dos atletas, fazendo com que sejam minimizados, e de preferência neutralizadas, os elementos prejudiciais ao rendimento atlético. Além disso, de acordo com Gonzalez e Garcês de Los Fayos (2009) e Olmedilla, Ortega, Andreu e Ortin (2010), o treino psicológico deve constituir uma prática 
habitual, em que deverão ser contempladas, além das competências psicológicas, estratégias de afrontamento, incidindo-se na sua aprendizagem e no seu uso, não esquecendo os processos de reflexão e tomada de decisão, tanto a nível individual como coletivo.

Nas últimas décadas multiplicaram-se os estudos no âmbito da caracterização do perfil psicológico de prestação em diversas modalidades desportivas, nomeadamente andebol (Lázaro, Casimiro e Fernandes, 2005; Moreira \& Vasconcelos-Raposo, 2012); rugby (Golby \& Sheard, 2004; Golby, Sheard \& Lavallee, 2003); natação (Dias \& Vasconcelos-Raposo, 1995; Vasconcelos-Raposo, 2003); Kung-Fu (Kuan \& Jolly, 2007); futsal (Silva \& Vasconcelos-Raposo, 2002); karate (Gouveia, 2011) no futebol em particular (Almeida \& Teixeira, 2018; Almeida, 2010, 2013; Carvalho \& Vasconcelos-Raposo, 1998; Guadalupe, 2010; Mahl \& Vasconcelos-Raposo, 2005; Tavares \& Correia, 2006). Estes estudos permitiram constatar que os atletas de nível competitivo mais elevado apresentam índices superiores nos skills psicológicos, quando comparados a atletas de nível inferior. Entretanto, estes estudos tendem a não comtemplar os atletas do sexo feminino facto que mereceu atenção no presente estudo.

O interesse por esta temática emerge do facto de nos últimos anos se constatar um maior interesse por parte dos treinadores ao manifestarem vontade em apostar em programas de treino mental. De facto, os treinadores e atletas, sabem que as capacidades mentais são essenciais para o sucesso desportivo (McCann, 2004) e, por conseguinte, o sucesso desportivo depende de uma combinação de fatores físicos e mentais, pelo que é natural que os atletas mais bem-sucedidos se destaquem quer física, quer mentalmente (Weinberg \& Gould, 2017). Portanto, conhecendo os parâmetros e os fatores que estão relacionados com a prestação de um atleta, os treinadores serão capazes de aconselhar e de melhor elaborar planos que permitam corrigir as lacunas da prestação e potenciar os aspectos positivos da mesma, desde que tenham os conhecimentos necessários para tal. O que é conseguido com formação especializada em psicologia do desporto.

O treino das competências psicológicas proporciona aos desportistas maiores probabilidades de encontrarem soluções adequadas para responder às exigências e dificuldades que a competição lhes coloca (Pacheco, 2003). Para o mesmo autor, o paradigma de base desta prática tem amplas analogias com o treino físico, na medida em que, tal como acontece com as competências físicas, técnicas e motoras, as psicológicas também podem ser aprendidas, modificadas e melhoradas. De acordo com Vasconcelos-Raposo (1993), o treino mental visa maximizar o uso pleno das capacidades humanas dos atletas, fazendo com que sejam minimizados, e de preferência neutralizados, os elementos prejudiciais ao seu rendimento.

Conforme descrito, a realidade contextual de Moçambique, no que concerne à figura de psicólogo desportivo, desencadeia dois tipos de inquietações, nomeadamente: (i) como ultrapassar o sub-aproveitamento das múltiplas vantagens que a psicologia do desporto proporciona no âmbito da prestação desportiva dos atletas; e (ii) qual o perfil normativo das orientações cognitivas dos atletas (tarefa vs resultado), (iii) qual o perfil normativo das emoções; (iv) e qual a norma do perfil psicológico do futebolista moçambicano. A resposta as estas questões passa, essencialmente, pela intensificação da pesquisa em psicologia do desporto.

\section{Definição operacional das variáveis em estudo}

Autoconfiança: sentimento de crença nas próprias capacidades e metas pessoais (Durand-Bush, Salmela \& Green-Demers, 2001). É o grau de certeza que o individuo atribui a si próprio sobre a habilidade em ser bem-suce- 
dido numa determinada tarefa (Vealey, 1986).

Pensamentos negativos: é o estado emocional negativo, caracterizado por pensamentos negativos acompanhados de activação fisiológica, preocupação e apreensão, e dificuldade em interpretar os sintomas fisiológicos a que alguns designam de negativismo somático (Weinberg \& Gould, 2017).

Atenção: é sinónimo de concentração. É a interação com o meio envolvente, em uma determinada situação e num determinado espaço e tempo, onde o indivíduo estabelece contacto com os estímulos exteriores mais pertinentes, desprezando os não pertinentes, excepto quando é necessária uma interação com o passado e o futuro (Simões, 2008).

Imagética: é uma representação antecipativa quase-percetiva e quinestésica do comportamento para um objetivo, tendo como propósito aumentar as possibilidades de ocorrência desse mesmo comportamento A definição de imagética poderá ser sintetizada como sendo uma programação motora com o fim de otimizar o tempo da tarefa e a qualidade desta, de forma que o indivíduo se ajuste aos constrangimentos da tarefa com um elevado grau de sucesso (Simões, 2008).

Motivação: disposições, variáveis sociais e cognitivas que intervêm quando um individuo se envolve numa tarefa e na qual será avaliado, como por exemplo quanto entra em competição com outros ou tenta atingir um patamar de excelência. A motivação está intimamente associada com a orientação cognitiva, em particular nos que se refere à percepção do sucesso ou fracasso e a própria possibilidade de ser bem-sucedido ou fracassar (Simões, 2008).

Pensamentos positivos: refletem a habilidade de manter uma atividade cognitiva que tem por base as emoções positivas, recorrendo a fontes como a diversão, alegria, a determinação e o otimismo, permitindo que um atleta alcance altos níveis de ativação ao experimentar simultaneamente sensações de calma, baixa tensão muscular e controlo de atenção
(Wimberg \& Gould, 2017).

Atitude competitiva: comportamento relacionado com a vontade que o desportista emprega para conseguir alcançar os seus objetivos (Silva \& Vasconcelos-Raposo, 1997).

\section{Definição do problema e objetivos específicos}

As inquietações enumeradas levam-nos a seguinte pergunta de partida: Que características predominantes traçam o perfil psicológico de prestação do futebolista moçambicano nos domínios de autoconfiança, pensamentos negativos, atenção, imagética, motivação, pensamentos positivos e atitude competitiva?

Arrolado o problema, o presente estudo pretende comparar futebolistas moçambicanos por grupo etário, sexo, níveis competitivos, posição de jogo e anos de prática ao nível das variáveis autoconfiança, negativismo, atenção, imagética, motivação, positivismo e atitude competitiva.

\section{MÉTODOS}

O presente estudo caracteriza-se como descritivo, por descrever detalhadamente as informações inerentes aos futebolistas em estudo, exploratório por permitir maior ligação com o problema, possibilitando maior exploração das informações e características dos futebolistas, e com delineamento transversal pois, os dados foram recolhidos num único momento e enquadra-se no âmbito das metodologias quantitativas.

\section{Amostra}

Adotando uma amostragem não probabilística com viés de conveniência, a amostra seleccionada para o presente estudo foi composta por um total de 443 futebolistas moçambicanos participantes nas competições provinciais e nacionais referentes à época de 2016/2017, representando trinta e dois (32) clubes provenientes de oito (8) províncias de Moçambique, nomeadamente Cidade de Maputo, Maputo, Gaza, Inhambane, Sofala, Tete, Nampula e 
Niassa. Dentre eles 196 (44.2\%) são do sexo feminino e 247 (55.8\%) masculino.

O procedimento usado para a constituição dos grupos (variáveis independentes) foi preconizado de acordo com os estudos realizados por Almeida (2010). Por outro lado, quanto a posição táctica no jogo, foi usado como referência o estudo de Guadalupe (2010). Quanto às idades, os participantes foram distribuídos em três grupos, nomeadamente, 154 (34.8\%) com menor ou igual a 20 anos denominados GEI (Grupo Etário I), $153(34.5 \%)$ com idades entre os 21 e os 25 anos considerado GEII (Grupo Etário II) e 136 (30.7\%) com maior ou igual a 26 anos considerado GEIII (Grupo Etário III). Este agrupamento foi adaptado do modelo de Almeida (2010). No que se refere ao nível competitivo, os participantes foram distribuídos em dois grupos: nacional 163 (36.8\%) e provincial 280 (63.2\%). Relativamente às posições principais no jogo, 50 (11.3\%) dos participantes são guarda-redes, $96(21.7 \%)$ centrais, 103 (23.3\%) laterais, 110 (24.8\%) meio campistas e $84(19.0 \%)$ atacantes. Quanto aos anos de prática de futebol, os participantes foram distribuídos em três grupos: os que possuem menos ou igual a 5 anos de prática 119 (26.9\%), os que se encontram entre os 6 e os 10 anos $202(45.6 \%)$ e os que possuem igual ou maior a 11 anos 122 (27.5\%). Este critério foi adaptado do modelo preconizado por Moreira (2012). O critério adotado para a inclusão no estudo foi de ter idade igual ou superior a 18 anos.

\section{Instrumentos}

Para o presente estudo utilizámos o Questionário do Perfil Psicológico de Prestação que foi desenvolvido por Loehr (1986), cuja sua versão foi traduzida e validade para português por Vasconcelos-Raposo e colaboradores. O questionário é composto por 42 questões distribuídas nos sete skills psicológicos (auto- confiança, negativismo, atenção, visualização, motivação, pensamentos positivos e atitude competitiva), compostos por seis itens para cada, sendo o valor dos fatores calculado pelo somatório dos seus itens, respondidos de forma fechada numa escala tipo Likert de 5 pontos, que varia entre $1=$ quase sempre, 2 = frequentemente, 3 = às vezes, $4=$ raramente e 5 = quase nunca. Loehr (1986) define três níveis de preparação psicológica para a competição, consoante os valores obtidos em cada variável do PPP, que variam de 0 a 30 e indicam três níveis de preparação mental, isto é, de 0 a 19 (preparação mental muito fraca ou inexistente), de 20 a 25 (preparação mental média ou não sistemática) e de 26 a 30 (excelente preparação mental, realizada de forma sistemática).

\section{Procedimentos}

Para o processamento estatístico dos dados recolhidos foi usado o programa Statistical Package for the Social Sciences (SPSS), versão 22.0, com um nível de significância de 5\% ( $p \leq$ .05). Além da estatística descritiva utilizámos a análise de variância multivariada (ONE-WAY MANOVA) para a análise do efeito das variáveis independentes no conjunto das dimensões do PPP e de seguida, os testes Post Hoc para a comparação dos grupos e identificação de diferenças estatisticamente significativas entre os futebolistas em relação ao sexo, grupos etários, nível competitivo, anos de prática e posição do jogo.

O teste Pillai é considerado a estatística mais poderosa e robusta para uso geral, especialmente para desvios de suposições. Por exemplo, se a suposição de MANOVA de homogeneidade de variância-covariância for violada, o teste de Pillai é sua melhor opção. Também é uma boa escolha quando se possui tamanhos de células desiguais ou tamanhos de amostra pequenos (ou seja, quando $\mathrm{N}$ é pequeno $<8$ ). 


\section{RESULTADOS}

A seguir, apresentam-se os dados da consistência interna do instrumento, os resultados da comparação e diferenciação dos perfis psicológicos de prestação do presente estudo nas variáveis dependentes (autoconfiança, pensamentos negativos, atenção, imagética, motivação, pensamentos positivos e atitude compe- titiva) em função das variáveis independentes (grupos etários, sexo, nível competitivo, posição de jogo e anos de prática de futebol).

\section{Consistência interna do instrumento}

Foi realizada através do cálculo do Alpha de Cronbach a análise de consistência interna do instrumento PPP (quadro 1), num total de 42 itens.

Quadro 1

Alpha de Cronbach do teste do PPP

\begin{tabular}{cc}
\hline & Alpha de Cronbach \\
\hline PPP Total & .782 \\
Autoconfiança & .426 \\
Pensamentos Negativos & .492 \\
Atenção & .088 \\
Imagética & .582 \\
Motivação & .070 \\
Pensamentos Positivos & .542 \\
Atitude Competitiva & .516 \\
\hline
\end{tabular}

O valor de .782 revela-se como sendo muito próximo ao valor de referência (.80) permitindo considerar que a consistência interna da escala é boa.

\section{Normalidade dos dados}

No quadro 2, apresentamos a análise descritiva referente à média, desvio padrão, valor mínimo, valor máximo, assimetria e achatamento dos perfis psicológicos de prestação da globalidade da amostra.

Quadro 2

Resultados da análise descritiva do Perfil Psicológico de Prestação.

\begin{tabular}{cccccccc}
\hline $\begin{array}{c}\text { Perfil Psicológico } \\
\text { de Prestação }\end{array}$ & $\mathrm{N}$ & Mínimo & Máximo & Média & $\begin{array}{c}\text { Desvio } \\
\text { Padrão }\end{array}$ & Assimetria & Achatamento \\
\hline Autoconfiança & 443 & 10.00 & 30.00 & 23.474 & 3.952 & -.596 & .049 \\
Pensamentos Negativos & 443 & 7.00 & 27.00 & 15.887 & 3.614 & .091 & -.176 \\
Atenção & 443 & 7.00 & 25.00 & 14.772 & 3.199 & .221 & -.286 \\
Imagética & 443 & 6.00 & 29.00 & 14.630 & 4.226 & .443 & -.185 \\
Motivação & 443 & 6.00 & 25.00 & 13.252 & 3.423 & .583 & .271 \\
Pensamentos Positivos & 443 & 6.00 & 26.00 & 13.307 & 3.799 & .581 & .176 \\
Atitude Competitiva & 443 & 6.00 & 28.00 & 12.519 & 4.129 & .581 & -.171 \\
\hline
\end{tabular}

De acordo com os resultados acima podemos verificar que, de uma forma geral, com a excepção da dimensão autoconfiança, os futebolistas moçambicanos participantes deste estudo têm uma preparação mental muito fraca ou inexistente $(\leq 19)$. Os jogadores necessitam de integrar o treino mental nas suas rotinas diárias de treino para melhorar os skills psicológicos. A autoconfiança é o skill mais desenvolvido nestes futebolistas com uma média de 
23.47, todavia, a preparação mental média é realizada de forma não sistemática. Por outro lado, podemos aferir que os futebolistas são mais débeis na dimensão atitude competitiva com a média de 12.51 .

\section{Comparação em função dos grupos etários}

No quadro 3 são apresentados os resultados da comparação e diferenciação dos perfis psicológicos de prestação em relação aos grupos etários. Os resultados demonstram haver uma diferenciação dos perfis psicológicos. A análise de variância multivariada (MANOVA a um fator) demonstrou existir um efeito diferenciador significativo por parte da variável idade [Wilks' Lambda $=.926, \mathrm{~F}_{(14,868)}=$ 2.439, $p=.002$ e $\left.\eta_{\mathrm{p}}^{2}=.038\right]$. Os resultados das análises univariadas (ANOVA a um fator) dos testes Post Hoc, possibilitaram identificar diferenças significativas entre grupos etários nas dimensões autoconfiança, imagética e atitude competitiva.

A MANOVA ONE-WAY demostrou existirem diferenças entre grupos etários [Pillai's Trace $=.075, \mathrm{~F}_{(14,870)}=2.410, p=.003, \eta_{\mathrm{p}}{ }^{2}=$ .037]. A análise univariada da autoconfiança relativamente às comparações entre grupos etários evidenciaram não existir diferenças entre o GEI e o GEII ( $p=.001$; IC 95\% -2.00 e .138) e entre o GEI e o GEIII ( $p=.001$; IC $95 \%-2.783$ e -.577). Apesar de a diferença entre os grupos evidenciarem o valor de $p=$ .001 , tendo em consideração o intervalo de confiança em que o valor mais baixo é negativo e o valor mais alto é positivo, estes resultados não são interpretáveis.

Quadro 3

Comparação das competências psicológicas em função dos grupos etários.

\begin{tabular}{|c|c|c|c|c|c|c|}
\hline \multirow[b]{2}{*}{$\begin{array}{l}\text { Variáveis dependentes ( } \\
\text { Perfil Psicológico de Prestação) }\end{array}$} & \multicolumn{6}{|c|}{ Grupos Etários } \\
\hline & $\begin{array}{c}<\mathrm{ou}=20 \\
\text { anos } \\
(\mathrm{GEI}) \\
(\mathrm{N}=154) \\
\mathrm{M} \pm \mathrm{DP}\end{array}$ & $\begin{array}{c}21 \text { a } 25 \text { anos } \\
(\text { GEII }) \\
(\mathrm{N}=153) \\
\mathrm{M} \pm \mathrm{DP}\end{array}$ & $\begin{array}{c}>\text { ou }=26 \text { anos } \\
(\text { GEIII }) \\
(\mathrm{N}=136) \\
\mathrm{M} \pm \mathrm{DP}\end{array}$ & $\mathrm{F}$ & $p$ & $\begin{array}{l}\text { Diferenças } \\
\text { significativas } \\
\text { entre grupos } \\
\text { (Post Hoc) }\end{array}$ \\
\hline Autoconfiança & $22.63 \pm 4.07$ & $23.56 \pm 3.83$ & $24.31 \pm 3.78$ & 5.982 & .003 & $\begin{array}{c}\text { GEIII > } \\
\text { GEII > GEI }\end{array}$ \\
\hline Pensamentos Negativos & $16.09 \pm 3.38$ & $15.77 \pm 3.46$ & $15.77 \pm 4.01$ & .689 & .503 & ------- \\
\hline Atenção & $15.02 \pm 3.36$ & $14.77 \pm 3.24$ & $14.48 \pm 2.94$ & .722 & .487 & ------- \\
\hline Imagética & $15.41 \pm 4.04$ & $14.66 \pm 4.23$ & $13.70 \pm 4.26$ & 3.701 & .025 & GEI $>$ GEIII \\
\hline Motivação & $13.33 \pm 3.71$ & $13.35 \pm 3.32$ & $13.04 \pm 3.18$ & .625 & .536 & ------- \\
\hline Pensamentos Positivos & $13.55 \pm 3.95$ & $13.07 \pm 3.64$ & $13.27 \pm 3.80$ & 2.076 & .127 & ------ \\
\hline Atitude Competitiva & $13.38 \pm 4.14$ & $12.41 \pm 4.13$ & $11.64 \pm 3.96$ & 5.564 & .004 & GEI $>$ GEIII \\
\hline
\end{tabular}

$p \leq .05$

É importante salientar que a autoconfiança é a dimensão mais valorizada pelos futebolistas de todos os grupos etários. Quanto às dimensões menos valorizadas, encontrámos a motivação para os futebolistas do GEI e atitude competitiva para os futebolistas GEII e GEIII. Os índices de autoconfiança dos futebolistas aumentam com a idade. A atenção, a imagética e a atitude competitiva são desvalo- rizadas quanto mais alta for a idade dos futebolistas (quadro 3).

\section{Comparação em função do sexo}

No quadro 4, apresentamos os resultados da comparação e diferenciação dos perfis psicológicos de prestação em relação ao sexo. A análise de variância multivariada (MANOVA a um fator) demonstra que existe um efeito 
diferenciador significativo por parte da variável sexo [Wilks' Lambda $=.931, \mathrm{~F}_{(7,435)}=4.582, p$ $=.001$ e $\left.\eta_{\mathrm{p}}^{2}=.069\right]$. As diferenças significativas no sexo foram encontradas com base nos testes Post Hoc, nas dimensões autoconfiança, imagética, motivação, pensamentos positivos e atitude competitiva.

Como podemos ver, a autoconfiança é a

Quadro 4

Comparação das competências psicológicas em função do sexo.

\begin{tabular}{|c|c|c|c|c|c|}
\hline \multirow[b]{2}{*}{$\begin{array}{c}\text { Variáveis dependentes } \\
\text { (Perfil Psicológico de Prestação) }\end{array}$} & \multicolumn{5}{|c|}{ Sexo } \\
\hline & $\begin{array}{l}\text { Feminino } \\
\quad(\mathrm{F}) \\
(\mathrm{N}=196) \\
\mathrm{M}+\mathrm{DP}\end{array}$ & $\begin{array}{l}\text { Masculino } \\
(\mathrm{M}) \\
(\mathrm{N}=247) \\
\mathrm{M}+\mathrm{DP}\end{array}$ & $\mathrm{F}$ & $p$ & $\begin{array}{c}\text { Efeitos } \\
\text { estatísticos } \\
\text { entre grupos } \\
\text { (Post Hoc) }\end{array}$ \\
\hline Autoconfiança & $22.74 \pm 3.93$ & $24.06 \pm 3.88$ & 5.340 & .021 & $.338^{*}$ \\
\hline Pensamentos Negativos & $15.82 \pm 3.52$ & $15.94 \pm 3.69$ & 2.735 & .099 & .033 \\
\hline Atenção & $15.10 \pm 3.35$ & $14.51 \pm 3.05$ & .328 & .567 & .184 \\
\hline Imagética & $15.74 \pm 4.29$ & $13.75 \pm 3.97$ & 14.253 & .001 & $.481^{*}$ \\
\hline Motivação & $13.81 \pm 3.46$ & $12.81 \pm 3.34$ & 12.432 & .001 & $.294^{*}$ \\
\hline Pensamentos Positivos & $13.77 \pm 3.88$ & $12.94 \pm 3.70$ & 7.110 & .008 & $.219^{*}$ \\
\hline Atitude Competitiva & $13.31 \pm 4.13$ & $11.89 \pm 4.03$ & 12.292 & .001 & $.348^{*}$ \\
\hline
\end{tabular}

$p \leq .05$. Valores críticos de Cohen's d: ${ }^{*}>.2$ pequeno; ${ }^{* *}>.49$ moderado. $^{* * *}>.79$ grande.

dimensão mais valorizada pelos futebolistas, com destaque para os masculinos. Por seu turno, a atitude competitiva é a menos valorizada pelos futebolistas. Com a excepção da autoconfiança e pensamentos negativos, podemos notar que, diferentemente dos homens, as mulheres apresentaram índices mais elevados em todas as dimensões do PPP (quadro 4). Em função dos valores obtidos nos efeitos estatísticos verificamos que há um efeito pequeno na variável autoconfiança, em que homens pontuaram mais alto, e nas restantes variáveis foram as mulheres com pontuações mais altas e também com efeito pequeno nas variáveis imagéticas, pensamentos negativos, pensamentos positivos e atitude competitiva.

\section{Comparação em função dos níveis competitivos}

No quadro 5, apresentamos os resultados da comparação e diferenciação dos perfis psicológicos de prestação em relação aos níveis competitivos. A análise de variância multivariada (MANOVA a um fator) demonstra que existe um efeito diferenciador significativo por parte da variável nível competitivo [Wilks' Lambda $=.937, \mathrm{~F}_{(7,435)}=4.147, p=.001 \mathrm{e} \eta_{\mathrm{p}}{ }^{2}$ $=.063]$. As análises Post Hoc evidenciaram não existirem diferenças significativas em todas as dimensões do PPP.

Como podemos aferir no quadro 5 , os resultados demonstram que, com a excepção da autoconfiança, os futebolistas que atuam ao nível das competições provinciais apresentam índices mais altos em relação aos seus pares das competições do nível nacional ou primeira liga nacional. Portanto, no presente estudo, podemos evidenciar que quanto mais se sobe de divisão menores são os valores médios atribuídos às dimensões do PPP. A dimensão autoconfiança é a que apresentou índices mais altos para os dois grupos. A atitude competitiva é a dimensão menos valorizada pelos futebolistas dos dois níveis competitivos. Quanto aos efeitos estatísticos dos valores obtidos, verificamos que há um efeito pequeno na variável autoconfiança, em que os futebolistas do nível nacional pontuaram mais alto que os do provincial e nas restantes variáveis foram os atletas do nível provincial com pontuações 
Quadro 5

Comparação das competências psicológicas em função dos níveis competitivos.

\begin{tabular}{|c|c|c|c|c|c|}
\hline \multirow{3}{*}{$\begin{array}{l}\text { Variáveis dependentes } \\
\text { (Perfil Psicológico de Prestação) }\end{array}$} & \multicolumn{5}{|c|}{ Níveis Competitivos } \\
\hline & $\begin{array}{c}\text { Nacional } \\
\quad(\mathrm{N}) \\
(\mathrm{N}=163)\end{array}$ & $\begin{array}{c}\text { Provincial } \\
(\mathrm{P}) \\
(\mathrm{N}=280)\end{array}$ & $\mathrm{F}$ & $p$ & $\begin{array}{c}\text { Efeitos } \\
\text { estatísticos } \\
\text { entre grupos } \\
(\text { Post } \mathrm{Hoc})\end{array}$ \\
\hline & $\mathrm{M} \pm \mathrm{DP}$ & $\mathrm{M} \pm \mathrm{DP}$ & & & Cohen's d \\
\hline Autoconfiança & $24.47 \pm 3.82$ & $22.90 \pm 3.92$ & .000 & .999 & $.406^{*}$ \\
\hline Pensamentos Negativos & $15.40 \pm 3.69$ & $16.17 \pm 3.54$ & 1.452 & .229 & $.213^{*}$ \\
\hline Atenção & $14.52 \pm 3.09$ & $14.92 \pm 3.26$ & 2.610 & .107 & .126 \\
\hline Imagética & $13.56 \pm 3.91$ & $15.25 \pm 4.28$ & 1.001 & .318 & $.412^{*}$ \\
\hline Motivação & $12.93 \pm 3.19$ & $13.44 \pm 3.54$ & 1.005 & .317 & .151 \\
\hline Pensamentos Positivos & $12.72 \pm 3.71$ & $13.65 \pm 3.82$ & .270 & .603 & $.247^{*}$ \\
\hline Atitude Competitiva & $11.83 \pm 3.94$ & $12.92 \pm 4.19$ & .100 & .752 & $.268^{*}$ \\
\hline
\end{tabular}

$p \leq .05$. Valores críticos de Cohen's d: ${ }^{*}>.2$ pequeno; ${ }^{* *}>.49$ moderado. ${ }^{* *}>.79$ grande.

mais altas e também com efeito pequeno nas variáveis pensamentos negativos, imagética, pensamentos positivos e atitude competitiva.

\section{Comparação em função das posições de jogo}

No quadro 6, apresentamos os resultados da comparação e diferenciação dos perfis psicológicos de prestação em relação às posições de jogo. A análise de variância multivariada (MANOVA a um fator) demonstra que não existe um efeito diferenciador significativo por parte da variável posição principal no jogo [Wilks' Lambda $=.957, \mathrm{~F}_{(28,1559)}=.688, p=.889$ e $\left.\eta_{\mathrm{p}}{ }^{2}=.011\right]$. As diferenças significativas entre as posições de jogo foram encontradas com os testes Post Hoc, em todas as dimensões do PPP (ANOVA a um fator).

A MANOVA ONE-WAY demostrou não existirem diferenças entre posições de jogo [Pillai's Trace $=.044, \mathrm{~F}_{(28,1740)}=.689, p=.888$, $\left.\eta_{\mathrm{p}}^{2}=.011\right]$.

No quadro 6 , podemos constatar que a autoconfiança é a dimensão mais desenvolvida em todas as posições de jogo, com destaque para os guarda-redes que apresentam índices mais altos em relação aos seus pares.
Comparação em função dos anos de prática de futebol

No quadro 7, apresentamos os resultados da comparação e diferenciação dos perfis psicológicos de prestação em relação aos anos de prática de futebol. A análise de variância multivariada (ONE-WAY MANOVA) demonstra que existe um efeito diferenciador significativo por parte da variável anos de prática de futebol [Wilks' Lambda $=.899, \mathrm{~F}_{(14,868)}=3.408, p=$ .001 e $\left.\eta_{p}^{2}=.052\right]$. As diferenças significativas entre os anos de prática de futebol foram identificadas com os testes Post $\mathrm{Hoc}$, em todas as dimensões do PPP com excepção feita aos pensamentos negativos (ANOVA a um fator).

A MANOVA ONE-WAY demostrou existirem diferenças entre anos de prática de futebol [Pillai's Trace $=.103, \mathrm{~F}_{(14,870)}=3.367$, $\left.p=.001, \eta_{\mathrm{p}}{ }^{2}=.051\right]$. As análises univariadas relativamente às comparações entre os anos de prática de futebol evidenciaram existirem diferenças entre os grupos. $\mathrm{Na}$ autoconfiança, entre os gruposde $<$ ou $=5$ anos e de $>$ ou $=11$ anos $(p=.004$; IC 95\% -2.6892 -.3831) e entre os grupos de $<$ ou $=5$ anos e de 6 a 10 anos ( $p=.024$; IC 95\% -2.1780 -.1097). Na visualização, evidenciou existirem diferenças entre os grupos de $<$ ou $=5$ anos e de 6 a 10 anos ( $p=.001$; IC 95\% 1.12823 .3972$)$ e entre 


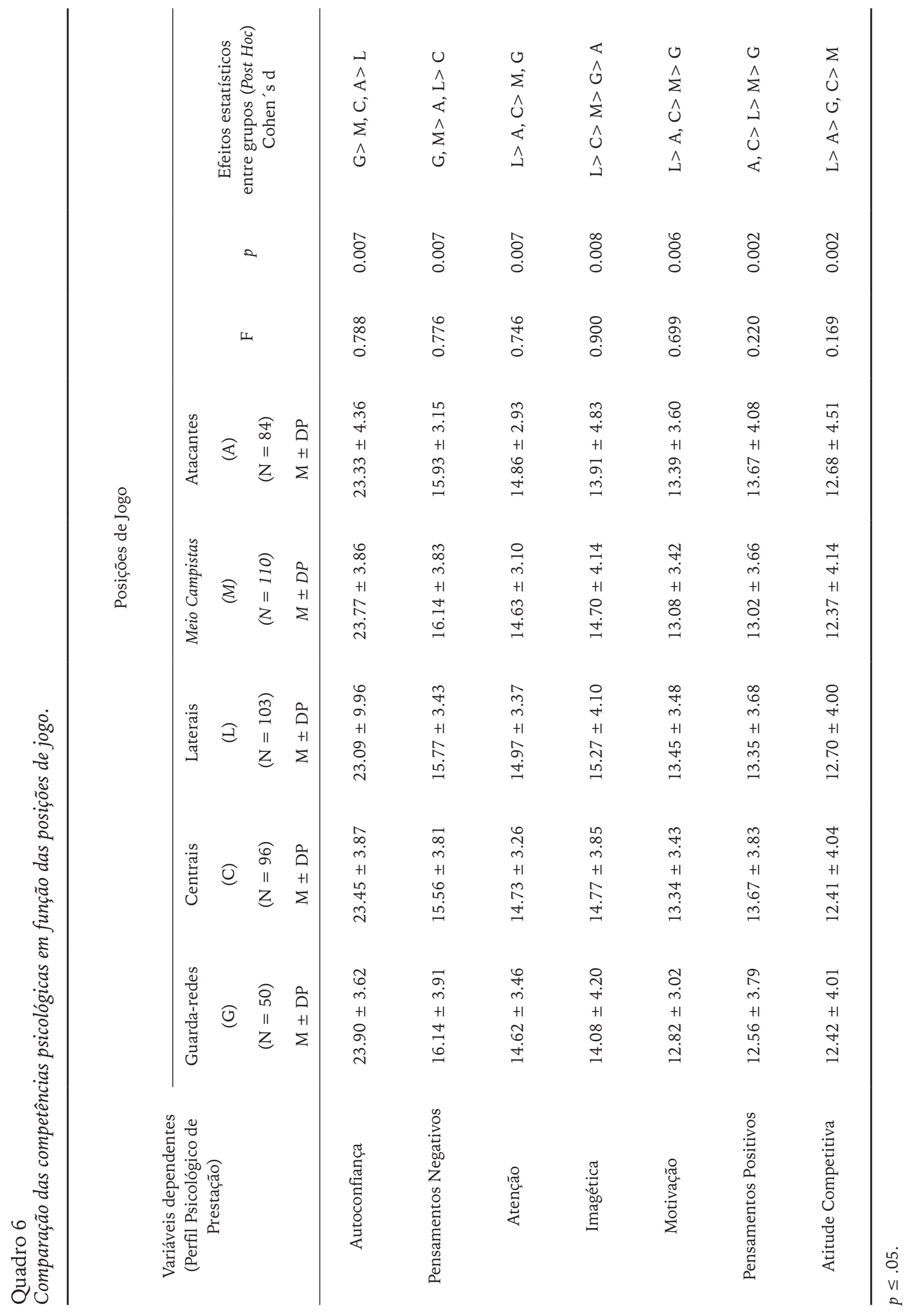


os grupos de $<$ ou $=5$ anos e de $>$ ou $=11$ anos ( $p=.001$; IC 95\% 1.67294 .2027$)$. Nos pensamentos positivos demonstrou existirem diferenças entre os grupos $<$ ou $=5$ anos e de 6 a 10 anos ( $p=.001$; IC 95\% .5314 2.5733) e entre os grupos de $<$ ou $=5$ anos e de $>$ ou $=$
11 anos $(p=.005$; IC 95\% .3641 2.6406). Na atitude competitiva evidenciou existirem diferenças entre os grupos de $<$ ou $=5$ anos e de 6 a 10 anos ( $p=.009$; IC 95\% .2651 2.5019) e entre os grupos de $<$ ou $=5$ anos e de $>$ ou $=$ 11 anos ( $p=.001$; IC 95\% .9849 3.4789).

Quadro 7

Comparação das competências psicológicas em função dos anos de prática de futebol.

\begin{tabular}{|c|c|c|c|c|c|c|}
\hline \multirow[b]{2}{*}{$\begin{array}{l}\text { Variáveis dependentes } \\
\text { (Perfil Psicológico de } \\
\text { Prestação) }\end{array}$} & \multicolumn{6}{|c|}{ Anos de Prática de Futebol } \\
\hline & $\begin{array}{c}<\mathrm{ou}=5 \text { anos } \\
(\mathrm{AP} 1) \\
(\mathrm{N}=119) \\
\mathrm{M} \pm \mathrm{DP}\end{array}$ & $\begin{array}{c}6 \text { a } 10 \text { anos } \\
(\mathrm{AP} 2) \\
(\mathrm{N}=202) \\
\mathrm{M} \pm \mathrm{DP}\end{array}$ & $\begin{array}{c}>\mathrm{ou}=11 \text { anos } \\
(\mathrm{AP} 3) \\
(\mathrm{N}=122) \\
\mathrm{M} \pm \mathrm{DP}\end{array}$ & $\mathrm{F}$ & $p$ & $\begin{array}{c}\text { Efeitos estatísticos } \\
\text { entre grupos (Post } \\
H o c \text { ) Cohen's d }\end{array}$ \\
\hline Autoconfiança & $22.53 \pm 4.27$ & $23.67 \pm 3.78$ & $24.07 \pm 3.78$ & 6.264 & .002 & AP3 $>$ AP2, AP1 \\
\hline Pensamentos Negativos & $16.18 \pm 3.32$ & $15.87 \pm 3.66$ & $15.64 \pm 3.62$ & .284 & .753 & ------- \\
\hline Atenção & $15.45 \pm 3.15$ & $14.73 \pm 3.13$ & $14.18 \pm 2.25$ & 5.902 & .003 & $\mathrm{AP} 1>\mathrm{AP} 3$ \\
\hline Imagética & $16.47 \pm 3.98$ & $14.21 \pm 4.15$ & $13.53 \pm 4.04$ & 14.162 & .001 & $\mathrm{AP} 1>\mathrm{AP} 2, \mathrm{AP} 3$ \\
\hline Motivação & $13.97 \pm 3.60$ & $13.25 \pm 3.32$ & $12.56 \pm 3.30$ & 6.860 & .001 & $\mathrm{AP} 1>\mathrm{AP} 3$ \\
\hline Pensamentos Positivos & $14.43 \pm 4.04$ & $12.88 \pm 3.55$ & $12.93 \pm 3.77$ & 7.295 & .001 & $\mathrm{AP} 1>\mathrm{AP} 3, \mathrm{AP} 2$ \\
\hline Atitude Competitiva & $13.76 \pm 4.04$ & $12.38 \pm 4.06$ & $11.53 \pm 4.06$ & 8.852 & .001 & $\mathrm{AP} 1>\mathrm{AP} 2, \mathrm{AP} 3$ \\
\hline Atitude Competitiva & $12.42 \pm 4.01$ & $12.41 \pm 4.04$ & $12.70 \pm 4.00$ & .169 & .002 & $\mathrm{~L}>\mathrm{A}>\mathrm{G}, \mathrm{C}>\mathrm{M}$ \\
\hline
\end{tabular}

$p \leq .05$.

Os futebolistas com mais experiência de prática apresentam valores mais altos na autoconfiança que os menos experientes que, por sua vez, são mais hábeis nas restantes dimensões. Quanto mais aumentam os anos de prática de futebol, mais aumentam os índices de autoconfiança dos futebolistas. Os dados revelam ainda que os índices das dimensões pensamentos negativos, atenção, imagética, motivação e atitude competitiva reduzem na medida em que os anos de prática de futebol aumentam.

\section{DISCUSSÃO}

O presente estudo foi delineado com a finalidade de comparar grupo etário, sexo, posição do jogo e anos de prática, a autoconfiança, negativismo, atenção, imagética, motivação, positivismo e atitude competitiva dos futebolistas moçambicanos. $\mathrm{O}$ resultado evidenciado remete-nos a elaborar uma discussão na visão psicológica respeitando a cariz cultural dos envolvidos.

Avaliamos a consistência interna das dimensões do PPP através do Alpha do Cronbach. Verificamos que existe uma consistência boa entre as mesmas ( $\alpha=.782)$, significando que todas estas dimensões não tem nada em específico pois, medem todas a mesma coisa, o PPP, considerando deste modo válido o instrumento de investigação. Contudo, as dimensões apresentam uma diferenciação da consistência que variam de pobre (imagética, pensamentos positivos e atitude competitiva) e muito pobre (autoconfiança, pensamentos negativos, atenção e motivação). Este facto remete-nos a que o uso das medidas de confiabilidade com o Alphado Cronbach não garante a unidimensionalidade ao questionário mas garante que ele existe e pode ser utilizado.

Os dados do questionário foram submetidos a uma verificação da normalidade usando a estatística descritiva com medidas de assimetrias e achatamentos. Quando as medidas de 
tendência central de dispersão e distribuição para cada dimensão, separadamente, observa-se que os coeficientes do momento de assimetria estão relativamente positivos com a excepção da autoconfiança, isto porque o afastamento do eixo de simetria acontece do lado direito da distribuição. Contudo, eles estão próximos do 0 pelo que podem ser associados a uma distribuição normal e consequentemente possuem uma boa capacidade para discriminar os futebolistas nestas questões.

No que diz respeito ao coeficiente do achatamento das dimensões do PPP, apresentam uma distribuição platicúrtica não diferenciando os futebolistas nestas dimensões.

Quanto ao contexto grupo etário, os dados possibilitaram identificar diferenças significativas entre os grupos nas dimensões autoconfiança, imagética e atitude competitiva, rejeitando a hipótese nula. Verificou-se ainda que os índices de autoconfiança dos futebolistas aumentam com a idade. Estes resultados, na dimensão autoconfiança em particular, vão ao encontro dos evidenciados por Mahl (2005), Luzio e Vasconcelos-Raposo (1995), Lázaro et al. (2005) e Almeida e Vasconcelos-Raposo (2010, 2013). Todavia, com atletas de basquetebol e de andebol, Linhares e Vasconcelos-Raposo (1998) e Casimiro (2004), respetivamente, não encontraram diferenças significativas nas dimensões do perfil psicológico nos diversos grupos etários.

Neste estudo, a atenção, a imagética e a atitude competitiva são desvalorizadas quanto mais alta for a idade dos futebolistas, indo ao encontro dos estudos de Almeida e Vasconcelos-Raposo (2010, 2013) e Almeida e Vasconcelos-Raposo (2013) na atitude competitiva, discordando com os achados de Almeida e Vasconcelos-Raposo (2013) na imagética, e de Guadalupe (2010) nas três dimensões. Esta constatação pode justificar-se pelo facto de os futebolistas moçambicanos com $\leq$ a 26 anos (GEIII) estarem a aproximar-se do final das suas carreiras desportivas e perderem inte- resse em aplicarem-se mais afincadamente na sua preparação para a competição desportiva (Lázaro et al., 2005). Estas três dimensões do Perfil Psicológico de Prestação são fundamentais para o rendimento desportivo dos atletas, uma vez que a atenção é a capacidade do atleta manter-se focado continuamente numa tarefa, centrando-se nos aspectos relevantes da tarefa e ignorando o que não interessa (Loehr 1986). Por sua vez, a imagética, segundo Weinberg e Gould (2017), nos atletas mais experientes, ajuda a aperfeiçoar habilidades e a prepará-los para tomarem decisões e fazerem ajustes preceptivos rápidos. Por outro lado, só as atitudes competitivas positivas podem ser benéficas para alcançar os objetivos propostos (Linhares \& Vasconcelos-Raposo, 1998), para o empenhamento e a vontade de ganhar (Simões \& Vasconcelos-Raposo, 1995).

Os índices das dimensões pensamentos negativos, atenção, imagética e atitude competitiva reduzem quanto maior for a idade dos futebolistas, sendo estes resultados contraditórios com os obtidos nos estudos de Mahl e Vasconcelos-Raposo (2005), Luzio e Vasconcelos-Raposo (1995) e Almeida \& Vasconcelos-Raposo (2010, 2013), Linhares \& Vasconcelos-Raposo (1998), Lázaro et al. (2005), Violas (2009) e Guadalupe (2010). Para o presente estudo, seria expectável que as habilidades psicológicas destes futebolistas do GEIII fossem mais fortes em relação aos futebolistas do GEI por estes, supostamente, possuírem muita experiência competitiva. Um outro pressuposto que pode associar-se a este fenómeno é, provavelmente, o facto de com a idade, estes atletas irem perdendo o interesse pela prática do futebol. Aferimos ainda que, nestes futebolistas, os índices mais baixos em todas as dimensões do PPP, foram encontrados nos futebolistas de GEIII e nos futebolistas do GEII.

No contexto sexo, o estudo preditivo evidenciou a existência de diferenças estatisticamente significativas $(\mathrm{p} \leq 0,05)$ nas dimensões autoconfiança, imagética, motivação, pensamentos 
positivos e atitude competitiva. Contudo, a autoconfiança foi a dimensão mais indicada pelos futebolistas do sexo masculino. Este destaque pode estar relacionado com o facto de estes serem, socialmente, tidos como os principais atores da modalidade de futebol, quando comparados com os femininos, sobre quem raramente recaem as atenções do púbico.

Em Moçambique é notável a ascendência dos futebolistas do sexo masculino em detrimento do feminino em vários subsistemas desportivos e níveis competitivos. Esta constatação pode ser interpretada numa visão cultural moçambicana onde pode-se entender um fenómeno social em que é condicionada pela evolução de modo de produção material, da decorrência da satisfação básica onde encontramos indivíduos atarefados com pouco tempo livre disponível para actividades desportivas. Ainda neste aspecto é importante referenciar que a mulher em Moçambique pertence á camada que dedica mais tempo às actividades que propiciam o rendimento de subsistência familiar. A título de exemplo, venda de produtos, actividades domésticas, cuidar dos mais novos. E em certos contextos, envolve-se em casamentos prematuros por pressão familiar como forma de obtenção de rendimento para a família original em forma de lobolo (dote financeiro-material recebido pelos progenitores da mulher), abrindo assim a impossibilidade de não envolvimento em práticas desportivas.

Nestes futebolistas, a atitude competitiva foi a dimensão menos valorizada e os valores médios mais baixos a evidenciarem-se nos masculinos. Por seu turno, a atitude competitiva reflete hábitos de pensamentos do atleta (Loehr, 1986), a vontade em querer conseguir alcançar os objetivos e a direção adotada (Silva \& Vasconcelos-Raposo, 1997). Este facto remete-nos a considerar que o sexo feminino valoriza as tarefas do treino de futebol dando maior dedicação e esforço, possibilitando assim o reconhecimento social visto como uma ferramenta positiva da emancipação da mulher.
Com a excepção da autoconfiança e pensamentos negativos, pode notar-se que, diferentemente dos futebolistas masculinos, os femininos apresentam índices mais elevados nas restantes dimensões do PPP, nomeadamente na atenção, imagética, motivação, pensamentos positivos e atitude competitiva. De acordo com esta relação, podemos aferir que as futebolistas mostram-se mais preocupadas com as suas habilidades psicológicas em relação aos masculinos, podendo ainda serem, de acordo com Williams e Krane (2001), bem-sucedidas, responsáveis e focalizarem-se para a tarefa tendo a dimensão atenção desenvolvida. Em ambos sexos, os futebolistas mostraram-se débeis na dimensão atitude competitiva.

Relativamente ao contexto níveis competitivos, os resultados preditivos evidenciaram não existirem diferenças estatisticamente significativas $(p \leq .05)$ das dimensões do PPP. Com a excepção da autoconfiança, os futebolistas que atuam nas competições provinciais, apresentaram índices mais altos em relação aos seus pares das competições nacionais ou primeira liga nacional. Portanto, nestes futebolistas, quanto mais sobe-se de divisão, menores são os valores médios atribuídos às dimensões do PPP. Estes resultados vão ao encontro dos estudos de Lázaro et al. (2005) nas dimensões autoconfiança, imagética, motivação e atitude competitiva e contrariam os encontrados por Mahl e Vasconcelos-Raposo (2005; 2007), Vasconcelos-Raposo (1993), Almeida (2010) e Almeida e Teixeira (2018), cujos resultados evidenciaram que quanto maior é o nível competitivo melhores são os valores relativos às dimensões avaliadas pelo PPP. Ademais, de acordo com Fernandes, Bombas, Lázaro e Vasconcelos-Raposo, (2007), é muitas vezes sugerido que quanto maior for o nível competitivo maior é o peso dos fatores psicológicos nos atletas.

Os resultados do presente estudo contrariam as evidências literárias consultadas segundo as quais, de acordo com Cruz e Viana (1996), os 
jogadores com maiores sucessos são os que competem ao nível mais elevado apresentando índices de confiança nas suas capacidades. Por outro lado, Loehr (1986) enfatiza que os atletas como níveis altos nas variáveis do PPP obtêm melhores rendimentos nas suas práticas desportivas. No caso particular da prestação dos futebolistas deste estudo, que atuam na segunda divisão, não significa que estes tenham acompanhamento psicológico em detrimento dos seus pares, mas sim, podem estar associados ao facto de estarem em ascensão profissional pois, este campeonato objetiva o alcance à primeira liga nacional de futebol.

A dimensão autoconfiança apresenta índices mais altos para os futebolistas do nível nacional em relação ao provincial. Estes resultados vão ao encontro dos encontrados por Carvalho (1998), Golbye e Sheard (2004), Linhares e Vasconcelos-Raposo (1998), Fernandes et al. (2007), Silva e Vasconcelos-Raposo (2002), Malh e Vasconcelos-Raposo (2005), Vasconcelos-Raposo (1993), Almeida (2010) e Almeida e Teixeira (2018). Neste sentido, é preciso acreditar que a autoconfiança dos atletas pode desenvolver-se sem que, necessariamente, este esteja no nível mais elevado da categoria profissional.

Os resultados alcançados da autoconfiança em futebolistas remete-nos a aliar-nos à ideia de Vealey, Hayashi, Garner-Holman e Giacobbi (1998) segundo a qual, os jogadores ganham confiança a partir das suas execuções técnicas, ao nível da mestria e da demonstração das suas habilidades e aumentam a sua autoconfiança quando atingem os seus objetivos. É com o treino das habilidades que se alcançam melhores resultados e, consequentemente, pode-se aumentar a autoconfiança do atleta. $\mathrm{Na}$ mesma ordem de ideias, Vasconcelos-Raposo (1993), referiu que o sistema de reforços positivos e negativos podem ou devem contribuir para o desenvolvimento da autoconfiança no atleta. Para o mesmo autor, o atleta autoconfiante é aquele que está seguro de si e da sua habilidade real. Portanto, trata-se, neste caso, do atleta com ótimas habilidades técnicas e domínio no desempenho da prática desportiva. Tanto os atletas que atuam no nível competitivo nacional como no provincial, são mais débeis na dimensão atitude competitiva; com os futebolistas da liga superior a mostrarem-se mais fracos.

Quanto às posições de jogo, a análise multivariada evidenciou existirem diferenças estatisticamente significativas $(p \leq 05)$ em todas as dimensões do PPP. Na comparação entre as posições de jogo, constatámos que a autoconfiança é a dimensão mais desenvolvida em todas as posições, com destaque para os guarda-redes que se evidenciaram também nos pensamentos negativos. Quando comparado com vários outros estudos, estes resultados coincidem totalmente com os achados de Mahl e Vasconcelos-Raposo $(2005,2007)$ e Almeida e Teixeira (2018), em que todas as posições tiveram valores mais altos na autoconfiança. Por um lado, os índices mais altos apresentados pelos guarda-redes nas dimensões autoconfiança e pensamentos negativos quando comparados com os seus pares, foram encontrados nos estudos de Mahl e Vasconcelos-Raposo (2005, 2007) para autoconfiança e Carvalho (1998) e Vasconcelos-Raposo (1994) para autoconfiança e pensamentos negativos. Contrariamente, estudos de Lázaro et al. (2005), Violas (2008), Almeida (2010), Guadalupe (2010), Almeida e Teixeira (2018) e de Moreira e Vasconcelos-Raposo (2012), a motivação foi a dimensão relativamente evidenciada pelos futebolistas.

Verificámos que quanto mais aproxima-se ao guarda-redes, os índices da autoconfiança aumentam para os laterais, indo ao encontro dos estudos de Almeida (2010) para os atacantes; Mahl (2005) para os meio campistas e Almeida e Teixeira (2018) para todas as posições. Esta tendência pode explicar-se pelo facto de os atletas defensivos terem maior responsabilidade em controlar a própria baliza do adversário, estabilizar e orientar a equipa durante o 
jogo em desportos coletivos e no futebol em particular. Os centrais e os atacantes possuem índices mais altos nos pensamentos positivos, sendo que para os atacantes, esta tendência vai ao encontro do estudo de Moreira e Vasconcelos-Raposo (2012) e os resultados contrários foram encontrados nos estudos de Mahl \& Vasconcelos-Raposo (2005, 2007), Violas (2009), Guadalupe (2010), Almeida e Vasconcelos-Raposo (2010) e Almeida e Teixeira (2018). Por sua vez, os laterais apresentam os índices mais altos na atenção, imagética, motivação e a atitude competitiva.

Quanto aos índices mais baixos das dimensões do PPP no presente estudo, podemos identificar nos guarda-redes as dimensões pensamentos positivos, motivação e atenção, indo ao encontro do estudo de Moreira e Vasconcelos-Raposo (2012) na dimensão pensamentos positivos, contrariando os resultados encontrados nos estudos de Almeida e Vasconcelos-Raposo (2010) e Almeida e Teixeira (2018) onde todas estas dimensões apresentaram valores médios altos, assim como para Mahl e Vasconcelos-Raposo (2005, 2007) na atenção e de Guadalupe (2010) nos pensamentos positivos. Os centrais apresentam índices mais baixos nos pensamentos negativos, indo ao encontro dos achados de Moreira e Vasconcelos-Raposo (2012).

Por seu turno, nos laterais e nos meio campistas, a atitude competitiva foi a que apresentou índices mais baixos, resultados semelhantes aos encontrados nos estudos de Mahl e Vasconcelos-Raposo $(2005,2007)$ nos meio campistas, diferentemente dos estudos de Almeida e Vasconcelos-Raposo (2010) e Almeida e Teixeira (2018). Os atacantes são mais débeis na imagética, contrariando os estudos de Almeida e Vasconcelos-Raposo (2010) e Almeida e Teixeira (2018), Mahl e Vasconcelos-Raposo (2005, 2007), Moreira e Vasconcelos-Raposo (2012) e Guadalupe (2010).

Relativamente ao contexto anos de prática de futebol, foram encontradas diferenças estatisticamente significativas nas dimensões autoconfiança, atenção, imagética, motivação, pensamentos positivos e atitude competitiva, indo ao encontro de estudos de (Carvalho, 1998; Luzio, 1995; Mahl \& Vasconcelos-Raposo, 2007). Entretanto os pensamentos negativos não apresentaram diferenças estatisticamente significativas. Nesta variável, os dados revelaram que a autoconfiança é a dimensão mais valorizada e, quanto mais maiores os anos de prática de futebol, mais aumentam os índices de autoconfiança. Estes resultados vão ao encontro dos estudos de Almeida e Vasconcelos-Raposo (2010, 2013), Lázaro et al. (2005), Mahl e Vasconcelos-Raposo (2005, 2007), Moreira e Vasconcelos-Raposo (2012) e Almeida e Teixeira (2018). Contrariamente, os índices da autoconfiança reduzem com a idade no estudo de Violas (2009). Geralmente, durante a prática desportiva, reside em atletas do GEIII o espírito de autoconfiança em relação aos GEI. Os atletasdo GEIII tendem a trazer bagagens de experiências para as adversidades das competições em diversas situações de jogo o que lhes dá confiança e as expectativas positivas à sua prestação e influência neles (Weinberg \& Gould, 2017). Para os mesmos autores, a autoconfiança é a crença de que você pode realizar com sucesso um comportamento desejado, cujo fator comum é que você acredita que vai conseguir.

Com a excepção da autoconfiança e dos pensamentos positivos, os dados revelaram que, os índices das dimensões pensamentos negativos, atenção, imagética, motivação e atitude competitiva reduzem na medida em que os anos de prática de futebol aumentam, colocando os menos experientes mais habilitados psicologicamente em relação aos seus pares. Quando comparados com outros estudos, estes resultados contrariam totalmente com os estudos de Almeida e Vasconcelos-Raposo (2010, 2013), Malh e Vasconcelos-Raposo (2005, 2007), Simões e Vasconcelos-Raposo 
(1995) e Almeida e Teixeira (2018), Guadalupe (2010) na dimensão atenção, Lázaro et al. (2004) nas dimensões autoconfiança, pensamentos negativos, atenção, motivação e atitude competitiva e Moreira e Vasconcelos-Raposo (2012) na autoconfiança, indo ao encontro ao estudo de Guadalupe (2010) na dimensão atitude competitiva e de Violas (2009) nas dimensões motivação e pensamentos positivos.

Ainda nesta vertente sobre os anos de prática de futebol, podemos aferir que os participantes são mais débeis na dimensão atitude competitiva com os mais experientes a revelarem valores mais baixos. Este fato entra em contradição com outros estudos pois, foram encontrados os valores mais baixos nas dimensões pensamentos negativos no Almeida e Vasconcelos-Raposo (2010, 2013), Guadalupe (2010), Lázaro et al. (2005), Moreira e Vasconcelos-Raposo (2012) e Almeida e Teixeira (2018).

No geral, estes resultados sobre a diferenciação nas habilidades psicológicas entre os futebolistas mais e menos experientes sugerem haver um conforto na autoconfiança dos GEIII, pelo tempo que atuam em seus clubes e na modalidade de futebol em particular, estando a caminho das suas reformas como praticantes. Os futebolistas menos experientes têm o maior desafio de manter os melhores níveis de performance em campo, o que lhes vai possibilitar desenvolver habilidades técnicas e manterem-se por longos anos mais habilidosos para garantirem as suas progressões na carreira desportiva. Em termos simples, atitude competitiva é de acordo com Silva e Vasconcelos-Raposo (1997), a vontade que o atleta emprega para alcançar os seus objetivos e a direção adotada para obter estas conquistas.

\section{CONCLUSÃO}

No presente estudo foi utilizado o Questionário do Perfil Psicológico de Prestação que apresenta uma consistência interna aceitável e uma distribuição normal e platicúrtica.

Os dados do presente estudo sugerem uma preparação mental muito fraca ou inexistente e uma necessidade de integrar o treino mental nas suas rotinas diárias de treino para melhorar as suas capacidades psicológicas. A autoconfiança tende a apresentar valores relativamente elevados. $\mathrm{O}$ estudo é um contributo para conhecimento e interpretação do PPP num ambiente sociocultural dos futebolistas moçambicanos. Parte dos resultados demonstram uma tendência de contradição com outras investigações e literatura, o que deve ser uma inspiração para estudos de PPP nos contextos do futebol de sociedades com nível de desenvolvimento relativamente frágil.

Com base nos resultados, parece evidente haver uma necessidade de criação de um novo figurino nas equipas técnicas dos clubes moçambicanos, assim como no planeamento de ações de formação para treinadores no âmbito da Psicologia do Desporto, para que estes possam saber como melhor utilizar e potenciar os contributos da preparação mental dos atletas para se obterem níveis mais altos de rendimento desportivo. Uma ideia que reforça as enunciações referidas, a título de exemplo, por Gonzalez e Garcês de Los Fayos (2009), Vasconcelos-Raposo (1991) e Olmedilla et al. (2010). Ações que dependem de políticas desportivas alicerçadas na conceção de um plano nacional de formação de treinadores onde a psicologia do desporto deverá constar. Estas são responsabilidades que recaem sobre os técnicos principais e dirigentes máximos dos clubes desportivos de futebol com vista a tornar esta prática importante para uma boa prestação desportiva.

\section{Agradecimentos:}

Nada declarado.

Conflito de Interesses:

Nada declarado.

Financiamento:

Nada declarado. 


\section{REFERÊNCIAS}

Almeida, L. M. O. M. (2010). Perfil Psicológico de Prestação, Orientações Cognitivas e Negativismo do Futebolista Português. (Dissertação de Mestrado, Universidade de Trás-OsMontes e Alto Douro). Disponível em: https://sigarra.up.pt/flup/pt/pub_geral. pub_view?pi_pub_base_id $=23311$

Almeida, L. M. O. M. (2013). Perfil Psicológico de Prestação, Orientações Cognitivas e Negativismo do Futebolista Português: Estudo Comparativo entre jogadores profissionais e amadores. (Dissertação de Mestrado, Universidade do Porto). Disponível em: https://core.ac.uk/ download/pdf/143399314.pdf

Almeida, L. M. O. M., \& Teixeira, C. M. (2018). Perfil Psicológico de Prestação de Futebolistas Portugueses. PsychTech \& Health Journal. 1(2), pp. 3 - 14. Disponível em: https://doi.org/10.26580/PTHJ.art5.2018

Bodas, A., Lázaro, J., \& Fernandes, H. (2007). Perfil psicológico de prestação dos atletas paralímpicos Atenas 2007. Motricidade, vol. 3, núm. 3, pp. 33-43. Disponível em: http://www.scielo.mec.pt/pdf/mot/v3n3/ v3n3a05.pdf

Carvalho, F. (1998). Caracterização do perfil psicológico de prestação do jogador de futebol nos diferentes campeonatos nacionais, $1^{\circ}$ divisão, $2^{\circ}$ divisão de honra, $2^{\circ}$ divisão $B$ e $3^{a}$ divisão nacional. (Monografia de licenciatura não publicada) Universidade de Trás-osMontes e Alto Douro, Vila Real.

Cruz, J., \& Viana, M. (1996). Motivação para a prática e competição desportiva. In J. Cruz (Ed.), Manual de Psicologia do Desporto (pp.305-331). Braga: Edições SHO. Disponível em: https://repositorium.sdum. uminho.pt/bitstream/1822/21084/1/ manual-cruz- 9 - s tres s $\% 20$ e $\% 20$ ansiedade\%20desporto.pdf

Durand-Bush, N.; Salmela, J. e GreenDemers, I. (2001). The Ottawa Mental Skills Assessment Tool (OMSAT-3). The Sport Psychologist, 15, 1-19. Disponível em: https://www.researchgate.net/ publication/232565048

Fernandes, H. M., Bombas, C., Lázaro, J. P, \& Vasconcelos-Raposo, J.J. (2007). Perfil Psicológico e Sua Importância no Rendimento em Vela. Motricidade, vol. 3, núm. 3, pp. 24-32. Disponível em: https://www.redalyc.org/ pdf/2730/273020486004.pdf

Garfield, C. A. \& Bennett, H. Z. (1984). Peak performance: mental training techniques of the world's greatest athletes. Los Angeles: Tarcher. Disponível em: https://www. amazon.com/Peak-Performance-TrainingTechniques-Greatest/dp/0446391158

Gonsález, J., \& Garcés De Los Faos, E. J. (2009). Plan de Entrenamiento Psicológico en el deporte de la petanca: En Búsqueda del rendimiento grupal óptimo. Revista de Psicología del Deporte. Vol. 18, núm. 1, pp. 87-104. Disponível em: https://www.redalyc.org/articulo. oa? id $=235119250006$

Golby, J., Sheard, M. \& Lavallee, D. (2003). A cognitive-behavioural analysis of mental toughness in national rugby league football team. Perceptual and Motor Skill, 96, 455-462. Disponível em: https:// europepmc.org/article/med/12776828

Golby, J., \& Sheard, M. (2004). Mental toughness and hardiness oss at different levels of rugby league. Personality and Individual Differences, 37(5): 933-942. Disponível em: https:// doi.org/10.1016/j.paid.2003.10.015.

Gouveia, P. (2011). Perfil Psicológico de Prestação, Orientações Motivacionais e Negativismo do Praticante de Karate de Elite. (Dissertação de Mestrado. Universidade De Trás-osMontes e Alto Douro). Disponível em: https://lucaskarate.files.wordpress. com/2016/05/msc_pgouveia.pdf

Guadalupe, T. M. C. (2010). Perfil Psicológico de Prestação e Orientações Cognitivas - Caso de estudo com jogadores de futebol de 11 do Chelsea F. C. e S. L. Benfica. (Dissertação 
de Mestrado, Universidade da Beira Interior, Covilhã). Disponível em: https:// ubibliorum.ubi.pt/handle/10400.6/1807

Golby, J., \& Sheard, M. (2004). Mental toughness and hardiness at diferent levels of rugby league. Personality and Individual Differences, 37, 933-942. Disponível em: https://doi. org/10.1016/j.paid.2003.10.015

Hogg, J. (2001). Ensino da preparação mental para a performance: Um modelo para os treinadores de crianças e jovens. In J. Adelino, J. Vieira\& O. Coelho (Eds.), Seminário Internacional Treino de Jovens "Pensar no futuro, Apostar na qualidade”. Lisboa: INFED.

Krane, V., \& Williams, J. M., (2006). Psychological characteristics of peak performance. In J. Williams (Ed.), applied sport psychology: Personal growth to peak performance (pp. 207-227). New York: McGraw-Hill. 5th Ed., New York: McGrawHill. Disponível em:https://www.scirp. org/(S(351jmbntvnsjt1 aadkposzje))/ reference/References Papers . aspx?ReferenceID $=1787153$

Kuan, G., \& Roy, J. (2007). Goal Profiles, Mental Toughness and its Influence on Performance Outcomes among Wushu Athletes. Journal of sports science $\mathcal{E}$ medicine, 6 CSSI-2, 28-33. Disponível em: https:// www.ncbi.nlm.nih.gov/pmc/articles/ PMC3809050/

Lázaro, J., Casimiro, E. \& Fernandes, H. (2005). Determinação do Perfil Psicológico de Prestação do Jogador de Andebol Português: Um estudo em atletas da Liga e da Divisão da Elite. O Portal dos Psicólogos, Gabinete da Psicologia e Educação da Universidade de Trás-os-Montes e Alto Douro, Portugal. Disponível em: https://www.psicologia. pt/artigos/textos/A0269.pdf

Loehr, J. E., (1986). Mental Toughness training for sport: Achieving athletc excellence. Lexington: The Stephen Greene Press. Disponível em: https://www.scirp. org/(S(351jmbntvnsjt1aadkposzje))/
reference/References Papers. aspx?ReferenceID $=1787156$

Linhares, A., \& Vasconcelos-Raposo, J. J. (1998). Caracterização do Perfil Psicológico de prestação do Jogador de Basquetebol. (Monografia de Licenciatura não publicada). Universidade de Trás-osMontes e Alto Douro, Vila Real.

Macnamara, A., Button, A., \& Collins, D. (2010). The role of psychological characteristics in facilitating the pathway to elite performance. The Sport Psychologist. 24(1):74-96. Disponível em: https://doi. org/10.1123/tsp.24.1.52

Mahl, A. C. \& Vasconcelos Raposo, J. J. (2005). Orientação Cognitiva de atletas profissionais de futebol do Brasil. Brasil. Motricidade (pp. 253-265). ISSN: 1646107X. Disponível em: https://www. redalyc.org/pdf/2730/273020412004.pdf

Mahl, A. C., \& Vasconcelos-Raposo, J. J. (2007). Perfil psicológico de prestação de jogadores profissionais de futebol do Brasil. Revista Portuguesa de Ciências do Desporto, 7(1), 80-91. Disponível em: http://www.scielo.mec.pt/pdf/rpcd/ v7n1/v7n1a09.pdf

Mccann, S. (2004). Applying sport psychology to the real world of athletes: a model of offensive and defensive mental skills. Coaching Volleyball. Vol. 23. pp. 250-255. Disponível em: http://www.smscs.dreamhosters. com/wp-content/uploads/2016/01/ mentalmodel.pdf

Moreira, J. M., \& Vasconcelos-Raposo, J. J. (2012). Perfil Psicológico de Prestação $e$ Orientações Cognitivas no Andebol. (Dissertação de Mestrado não publicada). Universidade de Trás-os-Montes e Alto Douro, Vila Real.

Murad, M. (2007). A violência e o futebol: Dos estudos clássicos aos dias de hoje. Rio de Janeiro: FGV Editora. Disponível em: https://www.ludopedio.com.br/biblioteca/ a-violencia-e-o-futebol/ 
Olmedilla, A., Ortega, E., Andreu, M., \& Ortin, F. (2010). Programa de intervención psicológica en futbolistas: evaluación de habilidades psicológicas mediante el CPRD. Revista de Psicología del Deporte, Vol 19(2), pp. 249-262. Disponível em: https://www.redalyc.org/ pdf/2351/235116352012

Rebelo, A. N. (1999). Estudo da fadiga no futebol: Respostas crónicas e agudas. (Tese de doutoramento não publicada). Universidade do Porto, Porto.

Silva, D., \& Vasconcelos-Raposo, J. J. (2002). Perfil psicológico de prestação e orientação cognitiva do jogador de futsal. (Dissertação de Mestrado não publicada). Universidade de Trás-os-Montes e Alto Douro, Vila Real.

Simões, P. (2008). Treino Mental em Natação: Aplicação do Novo Modelo de Definição de Objectivos. (Tese de Doutoramento não publicada). Universidade de Trás-osMontes e Alto Douro, Vila Real.

Simões, O., \& Vasconcelos-Raposo, J. J. (1995). Diferenças de Perfil Psicológico de Prestação, Ansiedade e Orientação Cognitiva Entre Quatro Equipas Juvenis de Basquetebol, Segundo a Classificação Obtida. (Monografia de Licenciatura não publicada). Universidade Trás-os-Montes e Alto Douro, Vila Real.

Silva, D., \& Vasconcelos-Raposo, J. J. (2002). Perfil psicológico de prestação e orientação cognitiva do jogador de futsal. (Dissertação de Mestrado não publicada). Universidade de Trás-os-Montes e Alto Douro, Vila Real.

Vasconcelos-Raposo, J. J. (1991). Contributo para a identificação do estado ideal para a prestação desportiva. Natação, 14 (4), 4-8. Portugal.

Vasconcelos-Raposo, J. J. (1993). Os factores Psico-socioculturais que influenciam $e$ determinam a busca da excelência pelos atletas da elite Portuguesa. (Tese de Doutoramento não publicada). Universidade de Trás-osMontes e Alto Douro, Vila Real.

Vasconcelos-Raposo, J., \& Carvalho, F.
(1998). Caracterização do Perfil Psicológico de Prestação do Jogador de Futebol nos diferentes Campeonatos Nacionais, $1^{a}$ Divisão, $2^{a}$ Divisão de Honra, $2^{a}$ Divisão $B$ e $3^{a}$ divisão Nacional. (Monografia de Licenciatura não publicada). Universidade de Trás-osMontes e Alto Douro, Vila Real.

Vasconcelos-Raposo, J. J. (2003). Motivação para a competição e treino: $O$ caso das seleções portuguesas de natação. Estudos de Psicologia do Desporto, Saúde e Actividade Física, 1, 67-84. Disponível em: https://www.researchgate.net/ profile/Jose_Vasconcelos-Raposo/ publication/259753825_Motivacao_ Para_A_Competicao_E_Treino_O_ Caso_Das_Seleccoes_Portuguesas_De Natacao_Motivation_For_Competition And_Training_The_Case_Of_The Portuguese_National_Swimming_Teams/ Links/0c96052d959185f3e0000000/ Motivacao-Para-A-Competicao-E-TreinoO-Caso-Das-Seleccoes-Portuguesas-DeNatacao-Motivation-For-CompetitionAnd-Training-The-Case-Of-The-Portuguese-National-Swimming-Teams.Pdf

Vasconcelos-Raposo, J. J., \& colaboradores (1995). Tradução e Validação de Três Testes Psicológicos: Perfil Psicológico de Prestação, Orientação Cognitiva para a Tarefa e para o Ego (TEOSQ) e Teste de Negativismo cognitivo, Somática e Autoconfiança (CSAI-2). (Ensaios não publicados). Vila Real: SDE-UTAD.

Vealey, R. S., Hayashi, S. W., Garner-Holman, M., \& Giacobbi, P. (1998). Sources of sport confidence: Conceptualisation and instrument development. Journal of Sport E Exercise Psychology 1998 Vol.20 No.1 pp. 54-80. Disponível em: https://doi. org/10.1123/jsep.20.1.54

Violas, C. G., (2009). Competências Psicológicas no Futebol de Alta Competição: um estudo comparativo entre equipas de sucesso $e$ de insucesso. (Dissertação de Mestrado. 
Universidade Fernando Pessoa). Disponível em: http://hdl.handle.net/10284/1575.

Weinberg, R. S., \& Gould, D. (2017). Fundamentos da Psicologia do Esporte e do Exercício ( $6^{\mathrm{a}}$ ed.). Porto Alegre: ARTMED. pp. 273-315.

Williams, J. M., (1991). Características Psicológicas del Alto Rendimento. In J. M. Williams (Ed.), Psicologia aplicada al deporte (196-207). Madrid: Biblioteca Nueva. Disponível em: https://dialnet.unirioja. es/servlet/articulo?codigo $=303122$
Williams, J. M., \& Krane, V. (2001). Psychological characteristics of peak performance. In J.M. Williams (Ed.), Applied Sport Psychology: Personal Growth to Peak Performance pp.137-147. Moutain View, CA: Mayfield. Disponível em: https://www.scirp. org/(S(czeh2tfqyw2orz553k1w0r45))/ reference/References Papers. aspx?ReferenceID $=1787189$ 